\title{
Proposta de integração entre ensino-extensão-pesquisa: conscientização ambiental do correto descarte do óleo de cozinha usado e sua caracterização
}

\section{Título em inglês}

1 Márcia Angelica F.S. Neves marcia.neves@ifrj.edu.br

1 Ivanilton Almeida Nery

1 Daniele Santos Corrêa

1 Rodrigo Curty Pereira

1 Juliana Cordeiro Silva

\section{RESUMO:}

O descarte inadequado do óleo de cozinha usado causa danos ao meio ambiente. A alternativa mais viável para esse problema é a reutilização do óleo como insumo para a obtenção de novos produtos como, por exemplo, sabão e biodiesel. A conscientização ambiental da população em relação aos resíduos gerados por todos é que irá minimizar tais impactos ambientais. Este trabalho teve como objetivo a conscientização da população quanto ao descarte adequado do óleo de cozinha usado e posterior avaliação do mesmo a partir de algumas propriedades físico-químicas. Todo o óleo recolhido foi enviado ao laboratório de pesquisa, filtrado e analisado quanto ao índice de acidez, índice de saponificação e índice de iodo. A partir dos resultados obtidos, observou-se que a utilização do óleo de cozinha não influenciou significativamente no índice de iodo em relação ao tempo de estocagem de seis meses. Já os parâmetros de acidez e saponificação sofrem alterações após três meses de estocagem.

Palavras-chave: Conscientização ambiental. Descarte inadequado. Óleo de cozinha usado.

\section{ABSTRACT:}

The improper disposal of used cooking oil causes damage to the environment. The most viable alternative to this problem is to re-use oil as a feedstock for obtaining new products such as in manufacturing soap and biodiesel. The environmental awareness of the population for wastes generated by all that will minimize such impacts. This study aimed to public awareness about the proper disposal of used cooking oil and further evaluation from some physicochemical properties. All oil collected was sent to the research lab, filtered and analyzed for acid index, saponification index and iodine index. From the results obtained, it was observed that the use of cooking oil did not significantly influence the iodine index in relation to the storage time of six months. The parameters of acidity and saponification undergo changes after three months of storage.

Keywords: Improper disposal. Environmental awareness. Used cooking oil. 


\section{INTRODUÇÃO}

As gorduras e os óleos são ésteres formados a partir da reação de ácidos graxos e glicerol, sendo chamados de glicerídeos, podendo ser de origem vegetal ou animal. Óleo de cozinha usado ou gordura podem ser utilizados para a produção de sabões pois podem sofrer reações de hidrólise básica. Essa reação de hidrólise básica ocorre quando os ésteres (óleos ou gorduras) são aquecidos na presença de uma base (como a soda cáustica - NaOH) e é chamada de reação de saponificação (ALLINGER, 1985).

Por muitas décadas observa-se a preocupação com os impactos ambientais causados pelo descarte incorreto de resíduos domésticos, os quais geram problemas de caráter social, ambiental e econômico. O óleo de cozinha usado é um dos resíduos que precisa ser tratado de forma adequada. Segundo a literatura, cada litro de óleo de cozinha descartado inadequadamente pode contaminar 20 mil litros de água (SEGATTO, 2013; NUNES, 2011).

A ABIOVE (Associação Brasileira das Indústrias de Óleos Vegetais) apresentou uma produção de óleo

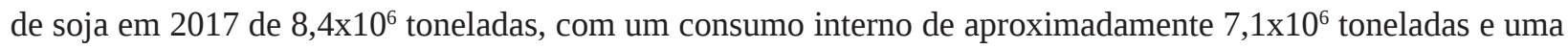

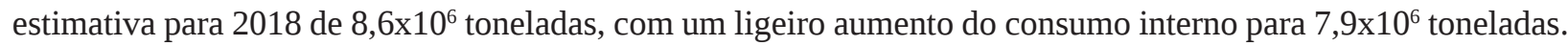
Com a grande geração de alimentos e produtos não duráveis, necessários a população, o Brasil se tornou um grande acumulador de resíduos. Logo, em julho de 2010, o Governo Federal implantou a Política Nacional de Resíduos Sólidos (PNRS), onde se obriga a implantação de uma logística reversa por meio do retorno de materiais industriais após o consumo. No capítulo II, artigo $3^{\circ}$ da Lei Federal 12.305 que institui a PNRS, logística reversa é definida como "Instrumento de desenvolvimento econômico e social caracterizado por um conjunto de ações, procedimentos e meios destinados a viabilizar a coleta e a restituição dos resíduos sólidos ao setor empresarial, para reaproveitamento, em seu ciclo ou em outros ciclos produtivos, ou outra destinação final ambientalmente adequada”. Sendo assim, após o uso, é necessária uma coleta adequada seguida da logística reversa e da conscientização da responsabilidade compartilhada pelo ciclo de vida dos produtos gerados (ZUCATTO et al., 2013). Diante disso, educadores também podem se tornar colaboradores ativos em relação ao descarte e/ou reutilização consciente do óleo de cozinha usado, bem como pela disseminação da prática de reuso e tratamento de resíduos.

Dentre as várias alternativas do reaproveitamento do óleo usado, encontradas na literatura, podem se destacar a produção de sabões a partir da hidrólise alcalina do óleo usado (LUCENA et al, 2014), a obtenção de biolubrificantes (NAGENDRAMMA \& KAUL, 2012; KANIA et al, 2015) e a produção de biodiesel através da transesterificação deste óleo utilizando metanol ou etanol (UDDIN et al, 2013, RAQEEB \& BHARGAVI, 2015). O glicerol, subproduto desta mesma produção alternativa, também pode ser utilizado como insumo para obtenção de sabões e sabonetes glicerinados.

Entretanto, a variada aplicabilidade observada requer uma caracterização específica do óleo de cozinha usado para ser considerado adequado para a obtenção de um produto específico (BORUGADDA \& GOUD, 2016). Por exemplo, para aplicação do óleo de cozinha usado para a produção de biodiesel, seu índice de acidez não deve ser superior a $0,5 \mathrm{mg} \mathrm{KOH/g}$ (Resolução ANP, n ${ }^{\circ}$ 45. 2014). Como os óleos usados são oriundos de diferentes procedências, torna-se necessária a caracterização dos mesmos.

Este trabalho teve como objetivo integrar o ensino, a extensão e a pesquisa dentro do IFRJ - campus Nilópolis através da conscientização da população do entorno quanto ao descarte adequado do óleo de cozinha usado e a caracterização desse óleo recolhido visando a possibilidade de reutilizá-lo na transformação em novos produtos. 


\section{METODOLOGIA}

O descarte incorreto do óleo de cozinha após a sua utilização gera um problema ambiental, tornando-se necessária a implantação de pontos de coleta em diversos locais: escolas, igrejas, supermercados, empresas, entre outros, onde o óleo é simplesmente entregue ou trocado por alguma mercadoria (WILDNER \& HILLIG, 2012). Desta forma, surgiu a ideia de fazer do IFRJ - campus Nilópolis um ponto de coleta, juntamente com a implantação da questão ambiental, com o auxílio dos alunos do curso de licenciatura em química e do curso técnico em química. A primeira etapa foi a solicitação da implantação de um ponto de coleta no pátio do campus e a conversa dos alunos envolvidos no projeto com alunos representantes das turmas dos cursos médio-técnico da referida instituição, bem como os representantes dos grêmios estudantis do ensino técnico e a comunidade local. Esta etapa teve como objetivo a realização de um trabalho informativo de conscientização ambiental, relacionado ao descarte correto do óleo de cozinha usado, alertando acerca dos prejuízos causados ao meio ambiente com o descarte inadequado do óleo de cozinha em pia ou em ralos. Todo o óleo recolhido foi enviado ao laboratório de pesquisa do campus, filtrado em peneira e armazenado em um recipiente para a coleta de amostras. A caracterização desse óleo foi realizada quanto ao índice de acidez, índice de saponificação e índice de iodo. Uma vez analisada a qualidade desse resíduo, o mesmo será destinado para a correta reutilização.

\section{1 Caracterização das amostras}

Após a formação do primeiro lote de óleo de cozinha usado, o mesmo foi filtrado e analisado quanto ao índice de acidez, de saponificação e de iodo, sendo realizado em triplicata cada análise. Em seguida, o mesmo foi estocado e tais análises foram repetidas a cada 3 meses, ou seja, foi feito um acompanhamento das propriedades desse óleo a fim avaliar a possível degradação do mesmo. Desta forma, a caracterização do lote foi feita no tempo zero (imediatamente após o fechamento do lote), três meses após e seis meses depois.

\section{2 Índice de Saponificação}

Foram pesadas cerca de $2 \mathrm{~g}$ de amostra, em balança analítica marca Sartorius e transferida para um balão $250 \mathrm{~mL}$ de fundo chato conforme norma da ABNT NBR 10448. Adicionou-se 25,00 mL de solução etanólica de hidróxido de potássio e foi feito refluxo por 1 hora. Após esta etapa, o sistema foi resfriado e adicionou-se solução indicadora de fenolftaleína, ocorrendo a titulação com solução padrão de HCl 0,5 mol/L. Foi feito, simultaneamente, o ensaio em branco.

\section{3 Índice de Acidez}

O índice de acidez é definido como a quantidade (mg) de hidróxido de potássio necessária para neutralizar os ácidos graxos livres presentes em $1 \mathrm{~g}$ da amostra de óleo. O índice de acidez revela o estado de conservação do óleo, visto que a decomposição dos glicerídeos é acelerada pelo aquecimento e pela luz, levando a formação de ácido graxo. Seguindo a norma ABNT NBR 11115:2014, foram pesados 5 g de amostra e transferidos para um erlenmeyer. Acrescentou-se $100 \mathrm{ml}$ de mistura de éter etílico e etanol (1:1) e 2-3 gotas do indicador fenolftaleína. Foi feito a titulação agitando o conteúdo com solução padrão etanólica de hidróxido de potássio 0,1 mol/L até a mudança de cor do indicador.

\section{4 Índice de Iodo}

O Índice de iodo é uma determinação do grau de insaturação de um óleo, estando assim relacionado com a quantidade de duplas ligações presentes na amostra. É expresso como a quantidade em gramas de iodo absorvido por $100 \mathrm{~g}$ de óleo. Assim, quanto maior a insaturação de um ácido graxo, maior será a sua capacidade de absorção de iodo, fornecendo um maior valor do índice de iodo. Conforme norma ABNT NBR 9231:2012, uma massa de amostra de aproximadamente $3 \mathrm{~g}$, em balança analítica marca Sartorius, foi pesada em frasco Philips com tampa. Adicionou-se à amostra, $15 \mathrm{~mL}$ de clorofórmio e $25 \mathrm{~mL}$ de solução de Wijs. $\mathrm{O}$ frasco foi fechado, 
agitado suavemente e colocado em ambiente escuro por um determinado período de tempo. Passado esse tempo, adicionou-se $20 \mathrm{~mL}$ de solução de iodeto de potássio $10 \%$ e $150 \mathrm{~mL}$ de água deionizada. A solução foi titulada com solução padrão de tiossulfato de sódio 0,1 eqg/L até a coloração amarelo pálido. Adicionou-se goma de amido e a titulação prosseguiu até o desaparecimento da cor azul.

\section{$3 \quad$ RESULTADOS E DISCUSSÃO}

O trabalho de conscientização é contínuo e permanente dentro da Instituição. Como em qualquer instituição de ensino, escolas e universidades a diversidade de alunos e o fluxo de entrada e saída dos mesmos nos obriga a ter uma preocupação constante. Por isso, em termos de debates de conscientização ambiental com palestras, rodas de conversa, participação em eventos internos e congressos externos se mantém desde a criação do ponto de coleta e do início da caracterização do material recolhido.

Com relação ao trabalho científico de caracterização do óleo de cozinha usado e que gerou um primeiro lote, os resultados são apresentados nos Gráficos 1, 2 e 3. Conforme mencionado na metodologia, as análises foram realizadas em intervalos de 3 meses e sempre foram feitas análises em triplicata, sendo apresentado os valores médios dos resultados obtidos.

\section{Gráfico 1: Resultados do índice de saponificação médio para amostragens do Lote em diferentes tempos}

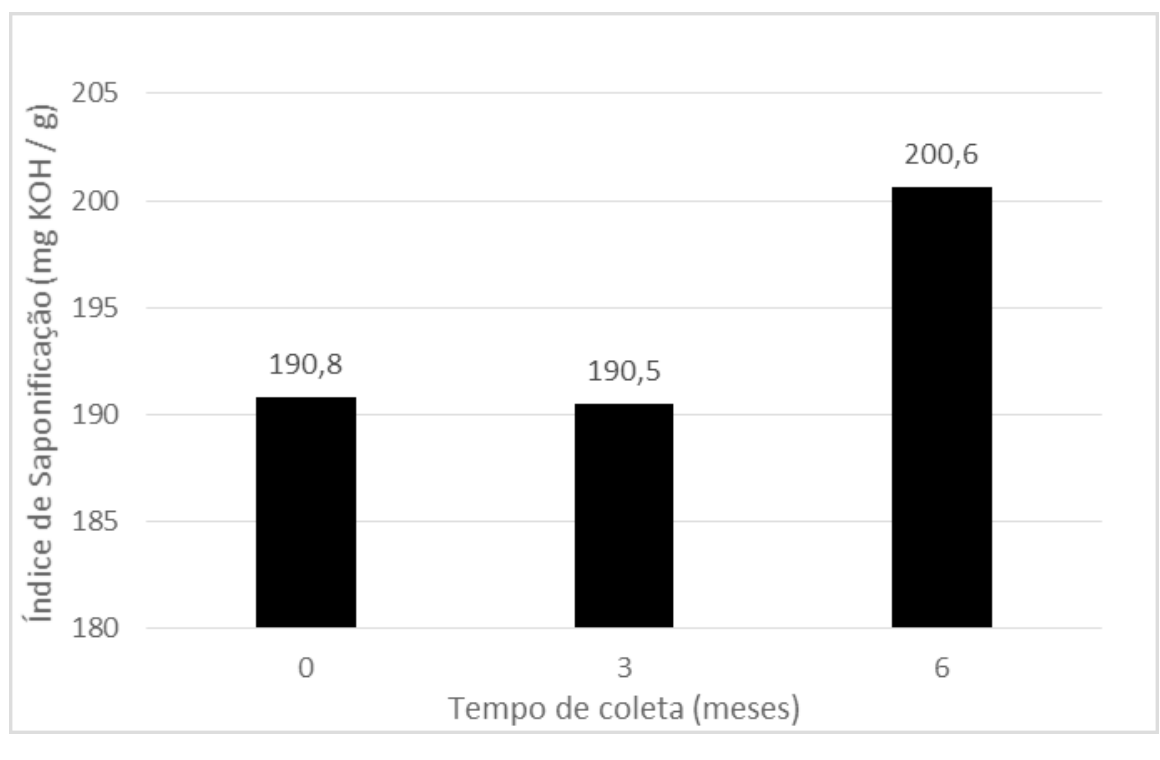

Fonte: ?

A faixa de valores aceitáveis para o índice de saponificação, segundo a Resolução RDC nº 482, de 23 de setembro de 1999 é entre 189 a $195 \mathrm{mg} \mathrm{KOH/g.} \mathrm{No} \mathrm{tempo} \mathrm{0,} \mathrm{ou} \mathrm{seja,} \mathrm{imediatamente} \mathrm{a} \mathrm{formação} \mathrm{do} \mathrm{lote,} \mathrm{o} \mathrm{valor}$ encontrado foi de 190,8 $\pm 2,041 \mathrm{mg} \mathrm{KOH/g}$. Após três meses de estocagem esse valor se manteve em 190,5 \pm 0,587 mg KOH/g. E com 6 meses de estocagem passa então para 200,6 \3,665 mg KOH/g. 


\section{Gráfico 2: Resultados do índice de acidez médio para amostragens do Lote em diferentes tempos}

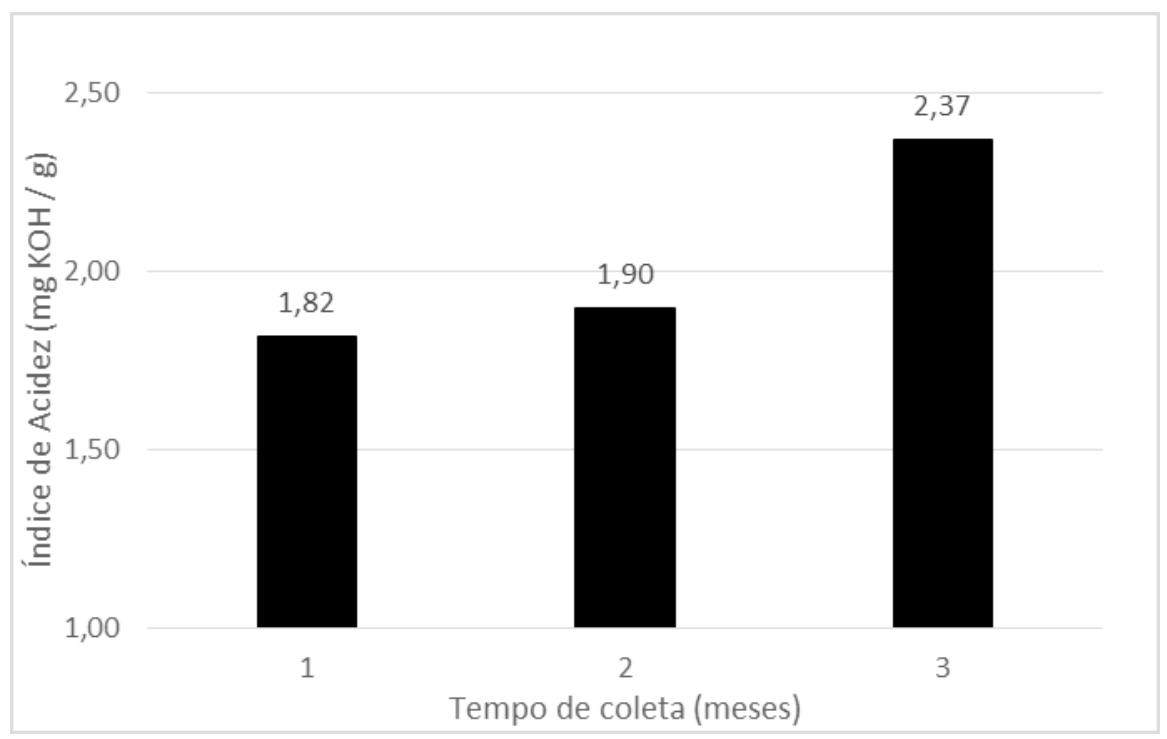

Fonte: ?

O valor máximo de índice de acidez segundo a Resolução ANP de nº 45 de 2014 é de 0,5 mg de KOH/g, para a utilização desse óleo na obtenção de biodiesel. Todas as amostras apresentaram um índice de acidez acima do desejado segundo a resolução acima, não sendo adequado para reuso na produção de biodiesel. Os valores encontrados conforme apresentados na figura 2 foram: 1,82 \pm 0,041 mg de KOH/g, 1,90 \pm 0,099 mg de KOH/g e 2,37 0,083 mg de KOH/g, para os tempos 0, 3 e 6 meses, respectivamente. A elevação do valor do Índice de Acidez indica que os triacilgliceróis presentes no óleo de cozinha sofrem hidrólise considerável após a utilização desse produto em altas temperaturas, o que acarreta na liberação de um maior número de ácidos graxos, aumentando, assim, o estado de deterioração do óleo.

\section{Gráfico 3: Resultados do índice de iodo médio para amostragens do Lote em diferentes tempos}

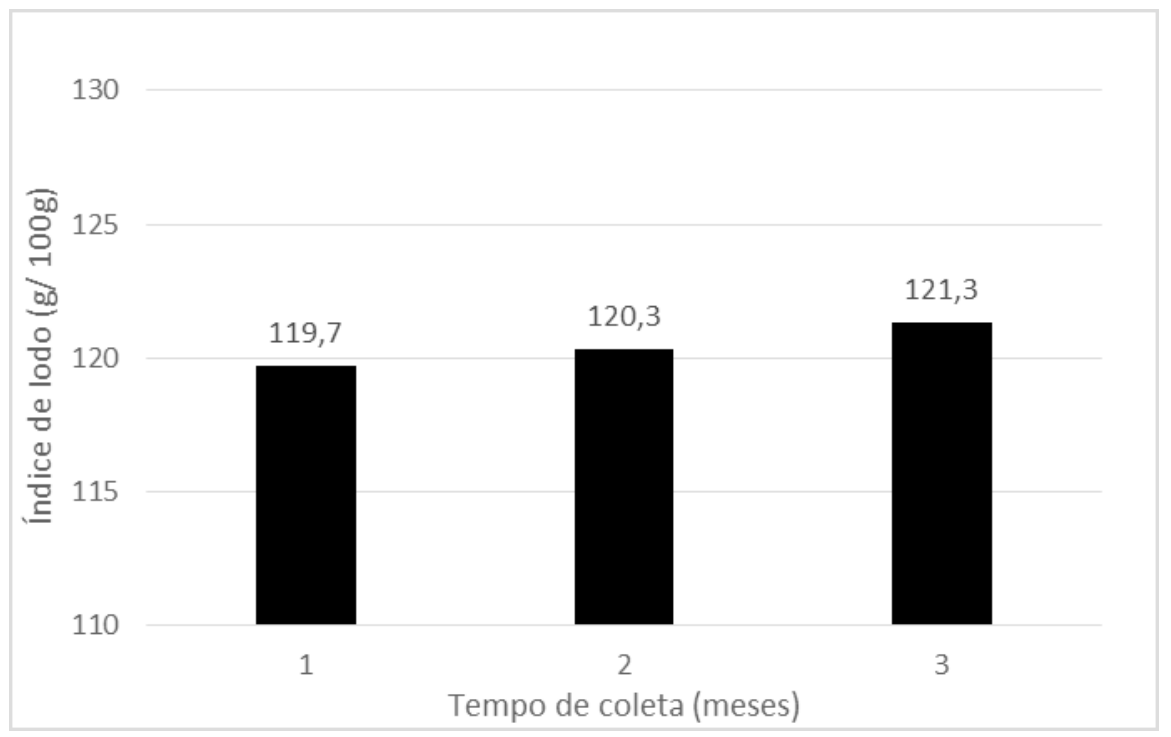

Fonte: ?

A Resolução RDC nº 482, de 23 de setembro de 1999 também especifica o índice de iodo, estipulando que esse valor deve se encontrar entre 120 a 143 g/100g. Todos os valores encontrados estão na faixa estipulada por 
esta resolução. Para o tempo 0, o índice de iodo foi de 119,7 $\pm 3,157 \mathrm{~g} / 100 \mathrm{~g}$, para o tempo estocagem de 3 meses foi $120,3 \pm 0,987 \mathrm{~g} / 100 \mathrm{~g}$ e para o tempo máximo estudado foi de $121,3 \pm 0,071 \mathrm{~g} / 100 \mathrm{~g}$.

A partir dos resultados apresentados acima, para cada propriedade determinada, foi feito uma análise de variância (ANOVA) a fim de avaliar se o fator tempo teve influência nas propriedades do óleo de cozinha usado. Foram comparados os resultados dois a dois.

A Tabela 1 apresenta os valores calculados para o teste $\mathrm{F}$ que foram comparados com o $\mathrm{F}$ crítico = 7,7086 para um nível de confiança de $95 \%$.

Tabela 1: Valores do teste F estatístico (teste ANOVA) comparados entre as amostras, em relação as respectivas análises $\left(\mathrm{F}_{\text {crítico }}=7,7086\right)$ :

\begin{tabular}{cccc}
\hline & & Valor F & \\
Análises & Tempo 0 - 3 & Tempo 3 - 6 & Tempo 0 -6 \\
\hline Índice de Saponificação & 0,05991 & 76,38 & 36,81 \\
Índice de Acidez & 1,689 & 39,76 & 105,9 \\
Índice de Iodo & 0,1100 & 2,676 & 0,7383 \\
\hline
\end{tabular}

Fonte: ?

Através da análise de ANOVA foi possível observar que o índice de iodo não foi estatisticamente influenciado pelo tempo de estocagem. Num período de estocagem de 6 meses, após o recebimento do óleo de cozinha usado pela instituição, não ocorreu alteração significativa nesses valores em cada tempo de estocagem estudado.

No caso da determinação do índice de acidez e do índice de saponificação foi observado que os valores encontrados para 0 e 3 meses não apresentaram alterações significativas em ambas as análises. Com o aumento do tempo de estocagem esses índices foram estatisticamente diferentes.

Através de análise ANOVA foi possível perceber que o tempo de estocagem não influenciou significativamente o índice de iodo. Com relação aos outros parâmetros avaliados, não se observaram diferenças significativas durante os três primeiros meses de estocagem. Havendo alteração significativa para um tempo de estocagem maior que três meses, conforme observado na tabela 2 pela comparação dos resultados do teste $\mathrm{F}$.

Diante de tais resultados, observou-se que a caracterização do óleo de cozinha usado permite a avaliação de como esse insumo pode ser aplicado na obtenção de novos produtos. Também foi possível, junto com a aplicação da ferramenta estatística, avaliar como o tempo de estocagem influencia na manutenção desses parâmetros.

A conscientização de todos levará a redução do descarte inadequado do óleo de cozinha usado, onde acaba causando o entupimento das tubulações, chegando ao sistema de esgoto e nos rios. Assim, é importante intensificar a educação ambiental nas escolas e na sociedade a fim de se aplicar a logística reversa proposta no PNRS.

\section{CONCLUSÃO}

A conscientização da população reduzirá a contaminação do meio ambiente e trará novos insumos para obtenção de produtos de maior valor agregado. O óleo de cozinha usado, avaliado nesse projeto, apresentou um alto valor do índice de acidez, não sendo um óleo adequado, por exemplo, para a obtenção de biodiesel (de acordo com os parâmetros exigidos pela ANP), se distanciando mais ainda dos parâmetros da ANP com o tempo de estocagem. O índice de saponificação foi também um parâmetro influenciado pelo tempo de estocagem, conforme pôde ser avaliado estatisticamente. E por fim, o índice de iodo não foi estatisticamente influenciado pelo 
tempo de estocagem, tornando-se possível manter o óleo avaliado sob armazenamento, sem que se modifiquem suas características de textura na confecção do sabão. Esse trabalho mostra que cada lote formado, ao longo do recolhimento do mesmo, precisa ser caracterizado para avaliar se o mesmo se encontra dentro de especificação para uma determinada aplicação. O IFRJ - campus Nilópolis se tornou um ponto de coleta e o mesmo continua sendo objeto de pesquisa aplicada e extensão para a síntese de sabão e/ou biodiesel. 


\section{REFERÊNCIAS}

ABIOVE (Associação Brasileira das Indústrias de óleos vegetais), disponivel em: http://www.abiove.org.br/site/ index.php, acessado em 20/04/2015.

AGÊNCIA NACIONAL DO PETRÓLEO, GÁS NATURAL E BIOCOMBUSTÍVEIS. Resolução ANP, nº 45. Brasília, 2014.

AGÊNCIA NACIONAL DE VIGILÂNCIA SANITÁRIA. Resolução RDC, nº 428. Brasília, 1999.

ALLINGER, N. Química Orgânica, 2 ed., Rio de Janeiro: Guanabara Dois, 1985.

BORUGADDA, V. B.; GOUD, V. V. Physicochemical and Rheological Characterization of Waste Cooking Oil Epoxide and Their Blends. Waste Biomass Valor, v. 1, n. 7, p. 23-30, 2016.

BRASIL. Lei n. 12.305/10, 2 de agosto de 2010. Prevê a prevenção e a redução na geração de resíduos, tendo como proposta a prática de hábitos de consumo sustentável e um conjunto de instrumentos para propiciar o aumento da reciclagem e da reutilização dos resíduos sólidos e a destinação ambientalmente adequada dos rejeitos. Lex: Diário Oficial da União, Brasília, Seção 1, de 3 de agosto de 2010. Legislação Federal.

KANIA, D.; YUNUS, R.; OMAR, R.; RASHID, S. A.; JAN, B. M. A review of biolubricants in drilling fluids: Recent research, performance, and applications. Journal of Petroleum Science and Engineering, v. 135, p. 177-184, 2015.

LUCENA, K. P.; ALBUQUERQUE, W. G.; MOURA, E. F. Alternativas ambientais: reciclagem do óleo de cozinha na fabricação de sabão. Informativo Técnico do Semi-Árido. v. 8, n. 2, p. 08-14, 2014.

NAGENDRAMMA, P.; KAUL, S. Development of ecofriendly/biodegradable lubricants: An overview. Renewable and Sustainable Energy Reviews, n. 16, p. 764-774, 2012.

NUNES, I. A. Reciclagem de Óleo Residual de Fritura nas Indústrias Alimentícias: um Estudo de Caso, 2011. Monografia de curso de Bacharel em Administração, Universidade de Brasilia.

PORTAL BRASIL. Óleo de cozinha pode ser descartado de forma consciente. Disponível em: <http:// www.brasil.gov.br/meio-ambiente/2014/08/oleo-de-cozinha-pode-ser-descartado-de-formaconsciente>. Acesso em: 20 de abril de 2015.

RAQEEB, M. A.; BHARGAVI, R. Biodiesel Production from Waste Cooking Oil. Journal of Chemical and Pharmaceutical Research,, v. 7, n. 12, p. 670-681, 2015.

SEGATTO, F. B. B. Conhecendo as Formas de Descartes do Óleo Saturado de Cozinha para verificar a Educação Ambiental na Escola. Revista de Gestão, Educação e Tecnologia Ambiental. v. 10, n. 10, 2013.

UDDIN, M. R.; FERDOUS, K.; UDDIN, M. R.; KHAN, M. R.; ISLAN, M. A.. Synthesis of Biodiesel from Waste Cooking Oil. Chemical Engineering and Science, v. 1, n. 2, p. 22-26, 2013.

WILDNER, Loreni Beatriz Arnold; HILLIG, Clayton. Reciclagem de Óleo Comestível e Fabricação de Sabão como Instrumentos de Educação Ambiental. Revista Eletrônica em Gestão, Educação e Tecnologia Ambiental REGET/UFSM, Santa Maria, v. 5, n. 5, p 813-824,2012.

ZUCATTO, L. C. Cadeia Reversa do Óleo de Cozinha: Coordenação, Estrutura e Aspectos Relacionais. RAE Revista de Administração de Empresas FGV-EAESP, São Paulo, v. 53, n. 5, p. 442-453, set./out. 2013. 